\title{
Experimental study on parabolic through solar collector
}

\author{
X.L. Wang ${ }^{1}$, H.S. Li ${ }^{1}$, Y.W. Lian' ${ }^{1}$, Y Yao ${ }^{1}$ \& C.T. Ye ${ }^{1}$ \\ ${ }^{1}$ Key Laboratory of Renewable Energy, Guangzhou Institute of Energy Conversion, Chinese \\ Academy of Sciences, Guangzhou 510640, China
}

KEYWORD: parabolic trough collector; normal direct solar radiation intensity; solar incident angle ABSTRACT: An experimental platform of parabolic through solar collector is established, and its thermal performance is evaluated. The results show that the receiver tube has an important effect on the system performance, and its performance deterioration will reduce the thermal efficiency. When the outlet temperature of solar collector is between 80 and $250{ }^{\circ} \mathrm{C}$, the transient system thermal efficiency does not decrease at higher temperature and its fit curve is parabola with an upward opening.

\section{INTRODUCTION}

Solar energy is one of the most promising renewable energy sources (Hinkley et al. 2013, Kost et al. 2012, Bosetti et al. 2012). Among solar thermal technologies, parabolic trough collector (PTC) is well accepted in the world. Up to now, the installed capacity of solar power plant using PTC reaches 3277.36 MW. According to the Chinese 12th Five Year Plan, 1000 MW capacity plant of concentrating solar power (CSP) will be established in 2015, and $3000 \mathrm{MW}$ capacity plant will be operated in 2020.

In recent years, in the world the solar thermal transition performance, the tracking and driving, the energy storage of the PTC solar power are being extensively researched (Cohen 1993, Kumaresan et al. 2012, Huang et al. 2012), and many plants is acting with commercial operation in tens of countries. In China there is not operational CSP plant, its related technology focus on simulation studies. For example, Xiong et al. $(2010,2012)$ calculated thermal performance based LS-2 PTC by numerical simulation; Cheng et al. (2014) researched solar energy distribution on the metal tube surface; simulation and experimental studies on receiver tube were carried out by Li \& Xia (2006) and Xu et al. (2012); Wang (2000) analyzed and simulated thermal flux distribution on receiver tube surface.

In this paper, referring to the foreign PTC solar power plant parameter in commercial operation, an experimental setup of PTC is established. The optical performance of the absorber was studied by means of Monte-Carlo ray-tracing (MCRT) method. The flow and heat transfer characteristics of the HTF in the absorber were investigated experimentally and theoretically. The effects of rectangular fins, heat flux distribution, and working conditions on the heat transfer performance were also discussed.

\section{PTC EXPERIMENT SYSTEM}

The experimental solar collector platform built in Sanshui, Guangdong province is shown in Fig. 1. The PTC is composed of metal frame, silver-plated glasses mirrors, the solar receiver, and the suntracking system. Synthetic oil is used as the heat transfer fluid. The PTC is oriented in EasteWest direction in order to ensure the normal incidence of solar radiation onto the collector at solar noon every day of the year. The main parameters of the PTC are represented in Table 1.

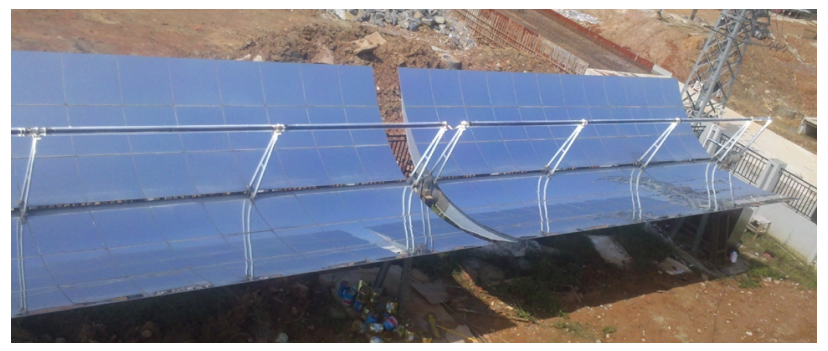

Fig 1. Photograph of the experimental platform 
Table 1 Specific parameters of the PTC platform

\begin{tabular}{cccc}
\hline Parameter & Value & Parameter & Value \\
\hline $\begin{array}{c}\text { collectors } \\
\text { width }\end{array}$ & $\begin{array}{c}5730 \\
\mathrm{~mm}\end{array}$ & $\begin{array}{c}\text { receiver } \\
\text { tube } \\
\text { length }\end{array}$ & $\begin{array}{c}4000 \\
\mathrm{~mm}\end{array}$ \\
$\begin{array}{c}\text { parabolic } \\
\text { trough focal } \\
\text { length } \\
\text { glass tube }\end{array}$ & $\begin{array}{c}1800 \\
\mathrm{~mm}\end{array}$ & $\begin{array}{c}\text { each collec- } \\
\text { tor length }\end{array}$ & $\begin{array}{c}12000 \\
\mathrm{~mm}\end{array}$ \\
$\begin{array}{c}\text { outer diame- } \\
\text { ter }\end{array}$ & $100 \mathrm{~mm}$ & $\begin{array}{c}\text { tracking } \\
\text { precision }\end{array}$ & $<0.1^{\circ}$ \\
$\begin{array}{c}\text { metal tube } \\
\text { outer diame- } \\
\text { ter }\end{array}$ & $70 \mathrm{~mm}$ & $\begin{array}{c}\text { driving pre- } \\
\text { cision }\end{array}$ & $<0.1^{\circ}$ \\
\hline
\end{tabular}

\section{RESULTS AND DISCUSSION}

The normal direct solar radiation intensity and heat oil temperature at outlet of the receiver tube at 29th, 30th are shown in Figs. 2 and 3, respectively.

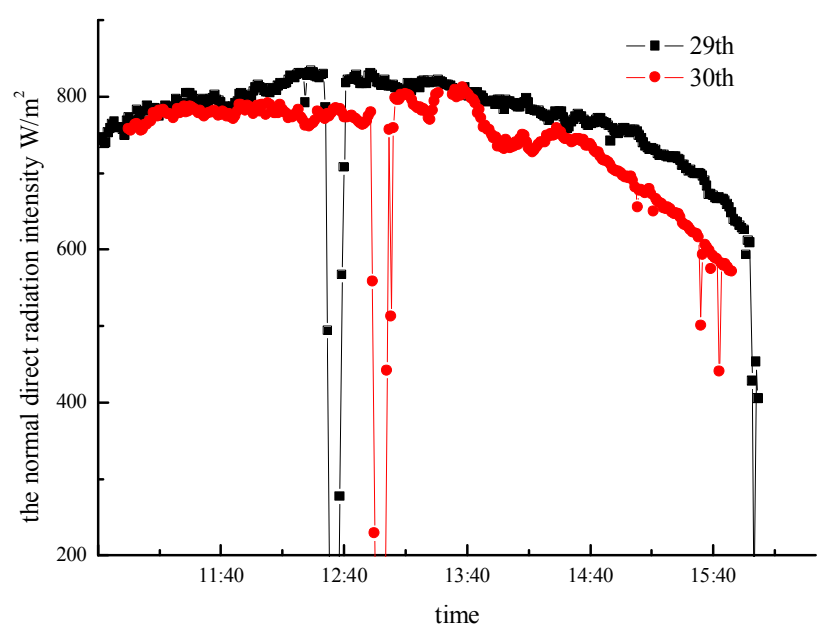

Fig 2. Normal direct solar radiation intensity

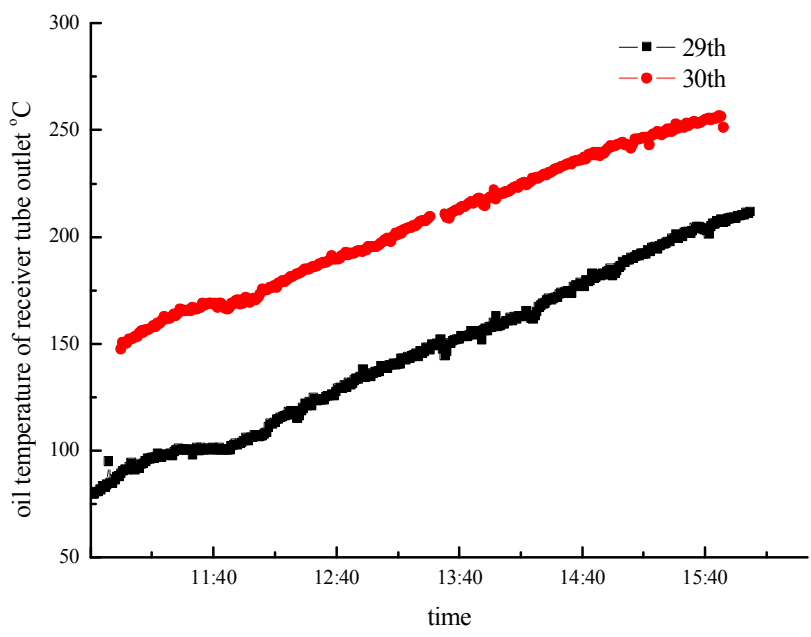

Fig 3. heat oil temperature in receiver tube outlet

To calculate momentary thermal efficiency of the PTC via some parameter value, which include heat oil temperature in inlet and outlet of receiver tube, direct solar radiation intensity on the PTC opening plane, flux and specific heat of heat oil in receiver tube, aperture area of the PTC. The direct solar radiation intensity is normal parameter by direct radiation instrument in the course of the experiment, the reality is that sunlight is not perpendicular to the PTC opening plane after tracking and driving running, there are some angle between sunlight and perpendicular line to the PTC opening plane, actual solar radiation intensity on the PTC opening plane is less than normal direct solar radiation intensity by direct radiation instrument, so their calculation formulae are as follow:

$\eta=W_{o} /\left(I_{k} \cdot S\right)$

$W_{o}=C \cdot V \cdot \rho \cdot \Delta T$

$I_{k}=I_{e} \cdot \sin \theta$

$\sin \theta_{e}=\left(1-\cos ^{2} \gamma \cdot \cos ^{2} \alpha\right)^{1 / 2}$ 
In Eqs. (1)-(5), $\eta$ is thermal efficiency; $\gamma$ is solar azimuth angle; $\alpha$ is solar altitude angle; $\sigma e$ is the angle between opening plane of the PTC on south-north tracking axis and horizontal plane; $\theta \mathrm{e}$ is the angle between direct sunlight and opening plane of the PTC; $I_{e}$ is the normal direct solar radiation intensity, $\mathrm{W} / \mathrm{m} 2 ; I_{k}$ is direct solar radiation intensity of opening plane of the PTC, W/m2; $S$ is the aperture area of the PTC, $\mathrm{m} 2$; Wo is the heat absorption power of heat oil in receiver tube from inlet to outlet, $\mathrm{W} ; C$ is the specific heat of heat oil at running temperature, $\mathrm{J} /(\mathrm{kg} \bullet \mathrm{k}) ; V$ is the volume flow rate of heat oil, $\mathrm{m} 3 / \mathrm{s} ; \rho$ is the density of heat oil at the running temperature, $\mathrm{kg} / \mathrm{m} 3 ; \quad \Delta T$ is the temperature difference between inlet and outlet of receiver tube, K. On a sunny day the energy of scattering light is below $1 \%$ for shinning light energy on metal surface of receiver tube of the PTC with big concentration ratio, so the factor of scattering light is ignored in Eq. (1).

Based on Eqs. (1)-(5) those change curve of solar incident angle and momentary thermal efficiency of PTC is given in Figs. 4 and 5. In Fig. 5 the efficient value of fitting curve do not always decreased with the increasing of temperature of working fluid in 29th and 30th, the curve shape is parabola with upward opening.

At 29th the thermal efficiency of the PTC fitting curve has two minimum values. One value appears at noon, and the other occurs between 13:00 to 14:00 p.m. This can be explained as follows: the sine curve of solar incident angle on the PTC opening plane is parabola with upward opening, which leads to the minimum value at noon. Around noon, the normal solar direct radiation intensity has less change, and it can be found from Eq. (3) that the direct solar radiation intensity variation on the PTC opening plane is similar to the variation of sine value of solar incident angle (as shown in Fig. 4). The heat loss of receiver tube increases with the increased working fluid temperature, and then the heat loss increasing and solar energy decreasing on PTC opening plane result in the thermal efficiency of PTC decreases with the working fluid temperature increasing. Although the heat loss increases with the increased working fluid temperature, after noon, the thermal efficiency increases, effect which is caused from the solar energy increasing with sine value increasing of solar incident angle is higher than, so the transient thermal efficiency of the PTC decreases with the increased working fluid temperature, a minimum value of thermal efficiency in the fitting curve occurs around noon at 29th.

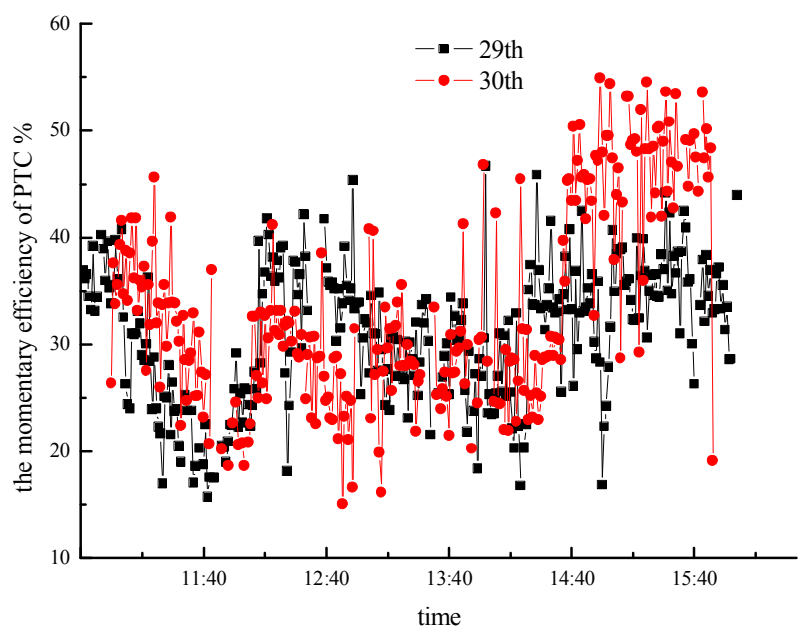

Fig 4. solar incident angle variation of PTC

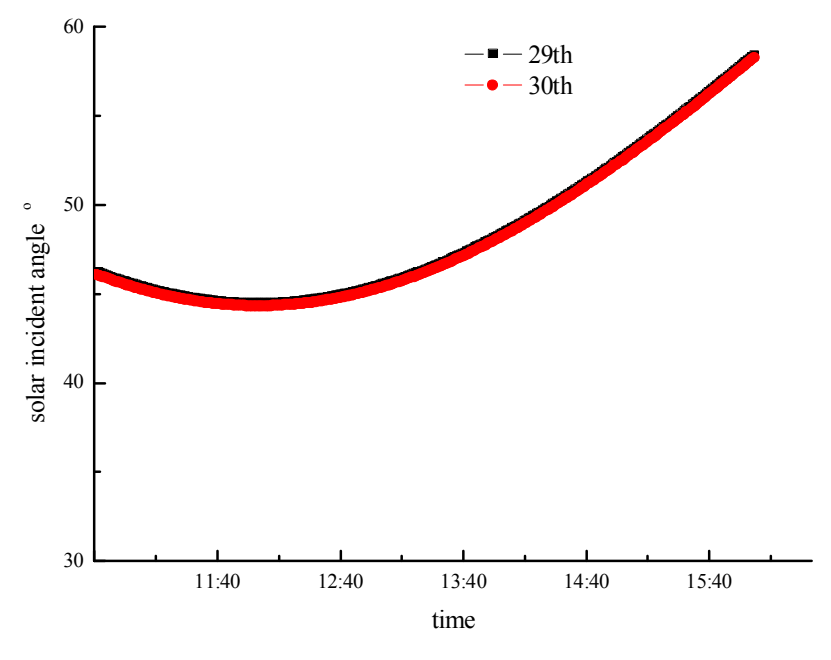

Fig 5. the momentary thermal efficiency of PTC

As the experiment proceeds, the normal solar radiation intensity decreases and the heat loss increases with working fluid temperature increasing; this leads to reduction in the thermal efficiency of the PTC. When the combination effect of these factors is higher than that of solar energy increasing of sine value variation of solar incident angle, the efficiency reaches its maximum value. After some time the gradient of the thermal efficiency of the PTC becomes positive, duo to the increased measure deviation of normal direct solar radiation intensity associate with the instrument, so the calcu- 
lated thermal efficiency value is higher than the actual value. Direct radiation instrument automatically records the measurements in working, firstly adjusting focus with two dimension must be manually made by adjusting horizon, solar declination angle, solar hour angle, altitude angle and direction angle before measure, then the paralleling state of direct sunlight to measuring light cylinder can be ensured within a period of time, so its normal direct solar radiation intensity measurement is precise in a short time, but measurement deviation have accumulation with the increasing of measuring time. At 29th again adjusting focus are multiply made by manual adjusting direct radiation instrument in the process of early testing, so the measurement deviation is small in the early testing stage; in the late stage direct sunlight deviates from the measuring light cylinder because no manual adjustment is conducted. With the deviation angle increasing, so decreasing solar energy which enter the bottom of light cylinder make direct radiation intensity measurement to be lower, the calculated solar thermal efficiency of the PTC is higher than the actual value, a extreme minimum value is shown on fitting curve. The location of focus deviation is confirmed by solar direct radiation instrument after the experiment.

In the early stage of 30th the calculated thermal efficiency fitting curve of the PTC is similar with that at 29th, but in the late stage of experiment the difference become obvious. There is only one minimum value of the thermal efficiency occurs at 30th fitting curve, the difference result from increasing tracking deviation of direct radiation instrument. In the early stage of 30th experiment only one adjusting focus is made, so in the late stage of 30th experiment the deviation of between direct radiation measurement and actual value increase with the increasing of measure time, so 30th deviation is bigger than 29th, then the calculated efficiency is higher. The difference of solar intensity can be found in Fig. 2.

The efficiency of the PTC is shown in Fig. 5, which is lower than the value given from Lippke (2000). This results from the performance deterioration of receiver tube of the PTC. Compared with the new receiver tube, the colour of selective coating of receiver tube which is installed and tested in the platform changes, and the getter disappears in some receiver tube. So the solar absorptance of the selective coating decreases, and thus the thermal efficiency of the PTC degrades.

\section{CONCLUSION}

A PTC experimental platform for application in CSP is finished. The thermal efficiency of the PTC is measured, and the effects of some parameters on the thermal efficiency are also discussed. It is found that based on experiment and theoretical analysis, the thermal efficiency of the PTC is presented. It is found that the shape of the fitting curve of thermal efficiency is parabola 'with an upward opening, which changes with time and working fluid temperature. This results from solar incident angle changing and tracking deviation. Besides, compared with the reference collector, the thermal efficiency of the PTC platform obtained here is lower, which is mainly due to the performance deterioration of solar receiver tube after long running.

\section{ACKNOWLEDGMENTS}

This work was supported by the Major Science and Technology Project of Guangdong Province, China (No. 2013A011405001, No. 2012A010800024, No. 2013A011404007), Science and Technology Planning Project of Guangdong Province, China (No. 2013B010405013) and Industry-StudyResearch Project of Guangzhou, China (No. 2013Y2-00091).

\section{References}

[1] Bosetti, V., Catenacci, M., Fiorese, G., et al. 2012. The future prospect of PV and CSP solar technologies: An expert elicitation survey. Energy Policy 49(10): 308-317.

[2] Cheng, Z.D., He, Y.L., Cui, F.Q., et al. 2014. Comparative and sensitive analysis for parabolic trough solar collectors with a detailed Monte Carlo ray-tracing optical model. Applied Energy 15(15):559-572.

[3] Cohen, G.E. 1993. Operation and Efficiency of Large-Scale Solar Thermal Power Plants. Optical Materials Technology for Energy Efficiency and Solar Energy Conversion, SPIEV2017, 332-337. 
[4] Hinkley, J.T., Hayward, J.A., Curtin, B., et al. 2013. An analysis of the costs and opportunities for concentrating solar power in Australia. Renewable Energy 57(9): 653-661.

[5] Kost, C., Engelken, M., Schlegl, T. 2012. Value generation of future CSP projects in North Africa. Energy Policy 46(7): 88-99.

[6] Huang, W.D., Hu, P., Chen, Z.S. 2012. Performance simulation of a parabolic trough solar collector. Solar Energy 86(2):746-755.

[7] Kumaresan, G., Sridhar, R., Velraj, R. 2012. Performance studies of a solar parabolic trough collector with a thermal energy storage system. Energy 47(1): 395-402.

[8] Li, M. \& Xia, C.F. 2006. Study on the characteristics and applications of evacuated tube heated by trough concentration system. Acta Energiae Solaris Sinica 27(1):90-95.

[9] Lippke, F. 1996. Direct Steam Generation in the Parabolic Trough Solar Power Plants: Numerical Investigation of the Transients and the Control of a Once - Through System. Solar Energy Engineering 118: 9-14.

[10] Wang, Z.F. 2000. The optical analysis and heat transfer of parabolic solar collector. Acta Energiae Solaris Sinica 21(1):69-76.

[11]Xiong, Y.X., Wu, Y.T., Ma, C.F. 2012. Prospect of solar thermal power and experimental research of parabolic trough thermal collector. Energy Technology and Economics 24(1): 53-56.

[12]Xiong, Y.X, Wu, Y.T., Ma, C.F., et al. 2010. Numerical study on thermal performance of parabolic trough collector. Journal of Engineering Thermophysics 31(3):495-498.

[13]Xu, R.J., He, Y.L., Xiao, J., etc al. 2012. Heat loss testing of parabolic trough solar receiver. Acta Energiae Solaris Sinica 33(1):99-104. 